\title{
Democratising utopian thought in participatory agenda setting
}

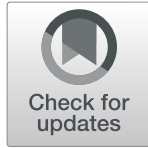

Niklas Gudowsky ${ }^{*}$ (D), Ulrike Bechtold, Walter Peissl and Mahshid Sotoudeh

\begin{abstract}
Engaging non-experts in matters of science and technology has been increasingly stressed in both rhetoric and action during the past decades. Under the call for moving participation upstream, agenda setting processes have been identified as viable entry point for laypeople's experiential and value-based knowledge into science,

technology and innovation governance (STI). Harnessing visioning for target setting promises to elicit such knowledge, whilst at the same time evading the dilemma of informing participants about STI that does not exist prior to engagement. To test such claims, we investigate a large-scale citizen-visioning exercise employed as an initiation of a transdisciplinary research and innovation agenda setting process, namely CIMULACT. In a comparable Europe-wide process, more than 1000 laypeople (citizens) produced 179 visions of desirable futures which built the basis for co-creating future research topics for advising the EU research and innovation programme Horizon 2020. We provide in depth insights into the visioning methodology for inclusion of citizens into STI agenda setting, and discuss room for methodological improvement regarding potential loss and gains of creativity and diversity of opinions considering empirical results of ex-post participant evaluation questionnaires $(n \approx 964)$. The discussed data shows a generally positive evaluation of the process and engagement, since citizens are in retrospective content with the process and visions, they would participate again in a similar event, and they are in favour of the EU to continue hosting such events in the future. However, citizens were rather sceptic whether the results actually (can/ will) have an impact on the stated aim of integration in research and innovation agenda setting.
\end{abstract}

Keywords: Visioning, Participatory foresight, Agenda setting, Public engagement

Visions and the democratisation of utopian thought Developing an image of the future is essential to any planning activity, thus, a basic trait in humans and even some non-human species [1,2]. Whilst there is a long way from episodic foresight to a structured one, the main aim remains the same, i.e. assessing future options to inform and improve present decisions. Developing and communicating socio-technical futures takes on various functions in the governance of innovation, such as mobilisation, legitimation, guidance, coordination, and sensemaking [3]. Such socio-technical futures may come in many forms and shapes, nevertheless in the past often as visions, scenarios and forecasts developed by

\footnotetext{
*Correspondence: niklas.gudowsky@oeaw.ac.at

Institute of Technology Assessment, Austrian Academy of Sciences, Apostelgasse 23, 1030 Vienna, Austria
}

\section{Springer Open}

individual or groups of experts. Within the realm of potential futures, the more populist images of the future may be rendered utopian-presenting either desirable targets or dystopian, containing implicit and explicit fears and warnings.

The terms vision and utopia are often used interchangeably, both referring to descriptions of desirable futures or idealised expressions of a future, which divert from the present, aiming at fostering transformative change [4]. However, whilst utopias describe imagined ideal worlds encompassing a holistic view of a future society in a functional narrative $[5,6]$, visions are descriptions of any imagined future-state, ideal or unideal from the respective author's perspective; hence, the terms of utopian vision-dystopian vision [7, 8]. Visions also may be very specific in terms of providing an outlook on futures of certain narrowly defined topics or a common

(c) The Author(s). 2021 Open Access This article is licensed under a Creative Commons Attribution 4.0 International License, which permits use, sharing, adaptation, distribution and reproduction in any medium or format, as long as you give appropriate credit to the original author(s) and the source, provide a link to the Creative Commons licence, and indicate if changes were made. The images or other third party material in this article are included in the article's Creative Commons licence, unless indicated otherwise in a credit line to the material. If material is not included in the article's Creative Commons licence and your intended use is not permitted by statutory regulation or exceeds the permitted use, you will need to obtain permission directly from the copyright holder. To view a copy of this licence, visit http://creativecommons.org/licenses/by/4.0/. 
target for a transition process. Furthermore, it is necessary to discern utopia from utopian thought, which is much more fragmentary and describes 'a wide range of visionary expressions' [9]. Utopian thought has portrayed ideas that led to societal transformations long before they became widely distributed and known, such as egalitarianism or feminism [10]. However, it does not necessarily have to advocate revolution, but can also inspire incremental change [5]. Levitas [11] describes utopian thought as a tool for transdisciplinary problem-solving which endorses holistic long-term thinking. Visions are not technological forecasts, but early insight into possible tomorrow's technologies and can provide sustainable orientation to inform today's decisions [12, 13]. As such, crafting desirable future states is 'a long-standing effort in human evolution and social change' [14]. Their function unfolds when visions are mentally contrasted to current society resulting in a 'facilitative effect on societal engagement' and thus transformation of the status quo [5]. Or as Berenskoetter [8] states 'visions call for agency to reduce or enhance the distance between what is and what could be'. He also discerns 'robust' and 'creative' visions: whilst the former integrate historically enduring traits and trends into envisioning futures that display resembling fractions of the present, the latter generate 'a new horizon whose primary function is to inspire and open up new paths into the future which hitherto were considered impossible'.

Visions can unfold a catalytic effect especially with regard to socio-technical developments, when they draw attention, change mind-sets, motivate behavioural change, followed by the allocation of funds [15, 16]. Visions and utopias challenge an existing order and inspire transformative change.

But even if a vision aims at transformation, it remains questionable to whom the respective future seems desirable. Obviously, a vision's ability to unfold transformative power reflects (established) societal power relations. Visions expressed by influential stakeholders describing futures within boundaries convenient to those in power, are much more likely to shape present decisions and actions than any vision expressed by those conventionally perceived as powerless, such as lay people. Often, a tiny elite of visionaries significantly influences innovation culture and technological change [17], especially if their visions become governance targets [18]. Visions may also exert power over actors, as changing arrangements increasingly becomes difficult, the more those actors invest and believe in a certain vision [8].

On the contrary, this results in an underlying ethical problem of technological development: 'most of the world's masses are in no position to anticipate for themselves either immediate benefits or improved long-term prospects from the forward march of technology' [19]. 'Profane' desires, such as the one for employment, may be easily overlooked when in competition with glaring high-tech visions of nano-technology or space colonisation, and thus render large parts of the population 'not having a future' [20]. Schneider and Lösch [21] describe how innovation governance and future making are often 'unequally distributed', and show how these can be democratised by democratising the very means to explore futures-in the exemplary case of 3D-printing in fab-labs. Also, Callaghan [22] identifies power dispersion as a necessary condition for future technological progress.

Democratising futures has been a growing stream in foresight, technology assessment (TA) and futures studies, and these fields have explored futures in a participatory manner for several decades [23-26]. TA, for instance, displays an 'inherent democratic nature' by including knowledge of various actor groups in developing and strengthening the thinking in alternative futures [27]. Fostering the democratising function of strategic foresight is important for obtaining 'collective and citizen ownership of the future' [28].

Numerous methods have been developed, remixed and applied to engage actors beyond the expert realm, especially with regard to public engagement in science and technology [29]. Within the growing framework of responsible research and innovation (RRI), engagement (inclusion) and anticipation are central pillars, among reflexivity and responsiveness. Building on existing concepts, such as upstream engagement or technology assessment, RRI demands an early inclusion of stakeholders and the public in research and development, which is meant to increase the possibilities to anticipate and discern how research and innovation can or may benefit society as well as prevent any negative consequences from happening' [30]. An analysis of the past European science policy framework programmes shows that their impetus changed from science education and communication towards governance and transformation of science and scientific institutions [31]. Eizagirre, Rodríguez [32] attest to RRI's aim of inclusive governance on the one hand, however, describing these aims' lingering contradiction with EU innovation policy's strategic imperative of competitiveness and economic development. Whilst for some socio-technical developments, this contradiction may be more serious than for others, Stirling [33] sees 'possibilities for achieving more truly sustainable and socially deliberate technological futures'. Inclusive research and innovation governance is often used synonymously with public engagement in science and technology, for which considerable resources- $€ 440$ mio.-were allocated within the previous EU framework programme for research and innovation ${ }^{1}$. Public engagement, however,

${ }^{1}$ See budget of SWAFS related work programmes from 2014-2020: https://ec.europa.eu/programmes/horizon2020/en/h2020-section/ public-engagement-responsible-research-and-innovation 
can only contribute to inclusive governance if its results are considered during decision-making and if they find implementation in any way, which they often do not, or as Braun and Könninger [34] conclude after reviewing and structuring scholarly criticism on public participation: 'Over the past one or two decades, the participatory turn has largely played out as a proliferation of standardised, stage managed, mostly government- or science-led arrangements of invited participation. Such arrangements frequently remain disconnected from actual policy-making or governance processes and thus more or less inconsequential'.

One way of democratising socio-technical futures is engaging laypeople into agenda setting in the course of research and innovation programming, as such an approach offers a means of escaping the Collingridge dilemma: 'citizens do not need a profound understanding or representation of a certain technology to express what needs it should help fulfil and which values it should reflect' [35]. Here, visioning-imagining desirable futures-without prior framing, promises to elicit such implicit and explicit knowledge [36]. Whenever discussing visions within the scope of this article, we are rather referring to results of utopian thought. Participants of the examined visioning exercise were explicitly instructed to imagine desirable (ideal) futures, albeit bearing in mind that a desirable future for one group of individuals may be undesirable to another. However, the visions mostly dealt with certain aspects of desired futures and therefore were to a large extent less holistic than full utopias (see above).

Besides being a key reference point for planning, participatory visioning activities hold process-level functions, such as capacity building, stakeholder empowerment, creating ownership, and developing accountability [13]. Recent empirical studies have shown that citizen-based agenda setting processes provide different outlooks on the same topics as well as unique topics when compared to expert-based foresight studies [37, 38]. Such participatory agenda setting has been identified as viable means for an early inclusion of laypeople's experiential and value-based knowledge into science, technology and innovation governance [35]. If the visioning process is conducted in a creative and fair democratic setting, it can increase legitimacy and accountability of agenda setting processes and therefore research and innovation agendas-if results are actually considered in decision-making [39].

\section{Aim and research question}

For public engagement in general, and for engaging citizens into agenda setting specifically, methods providing deliberation environments are an indispensable prerequisite. In this contribution, we investigate methodological and facilitatory aspects of a standardised trans-European visioning exercise that lay groundwork to a broader trans-
European agenda setting process for research and innovation. We are mainly interested in discussing the applied visioning method in the light of relevant literature, as well as in reflection of the results of an ex-post evaluation survey among participants. We are especially looking for areas of improvement for reaching the aim of democratising utopian thought and research and innovation governance.

After an overview of the context in which the process took place, we provide insights into the method of this visioning process itself and discuss its steps with regard to its theoretical and practical underpinnings. Then, we present and discuss data from the participants' ex-post evaluation questionnaires, and to finally draw lessons learned with regard to the visioning process specifically as well as for large large-scale consultation processes in general $^{2}$.

\section{Method \\ Citizens' visions in an Europe-wide agenda setting process}

In a comparable Europe-wide process, more than 1000 laypeople (citizens) participated in 30 parallel national visioning workshops (EU 28 + Norway and Switzerland), and produced 179 visions of desirable futures [40]. These visions built the basis for co-creating potential research topics for Horizon 2020 and possibly FP9. The visioning served as the initial step which was followed by an analysis of societal needs within the visions, a cocreation event for drafting potential research topics, another deliberation phase (online, offline) and a final policy workshop (see Fig. 1). Overall, this participatory research and innovation agenda setting process-CIMULACT-aimed to inform European research and innovation agendas. Whilst we predominately examine the visioning method and citizens' evaluation of the event in this article, for readers interested in analysis of the content of the visions, there is abundant material available, see [37, 38, 41-43], for an impact assessment consult Hebáková, Ratinger [44].

\section{Visioning process}

The visioning process itself built on the visioning method within the established CIVISTI method [39]. The process was designed for a group of approximately

\footnotetext{
${ }^{2}$ The CIMULACT project (Citizen and Multi-actor Consultation of Horizon 2020) was a coordination and support action (CSA) funded under Horizon 2020, H2020-ISSI-2014-2015: Call for integrating Society in Science and Innovation, Topic ISSI-2-2014: Citizens and multiactor engagement for scenario building. It was coordinated by the Danish Board of Technology (DBT). The authors lead the work package designated to citizen visioning, which included method development and specification, training consortium partners for conducting the 30 national workshops, developing prompting material and the ex-post evaluation questionnaire.
} 


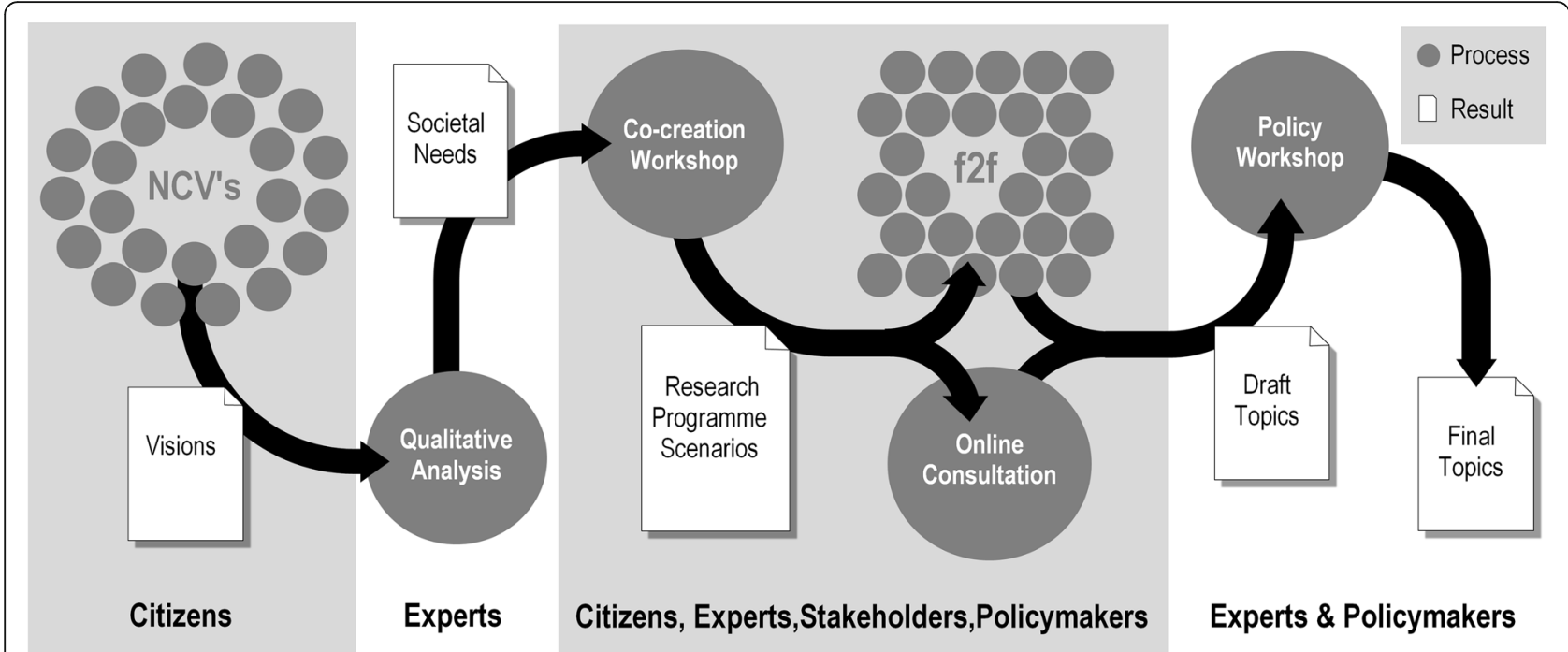

Fig. 1 CIMULACT methodology to co-create research topics [37]

36-40 participants distributed around six tables for a 1day workshop. The composition of participants at each table reflected a maximum possible diversity with regard various socio-demographics described in the next section. The process followed a standardised script. Its main steps can be summarised as follows: sharing knowledge on the past; visual inspiration and brainstorming; clustering of ideas; imaginary time travel; creating individual futures; creating shared futures; market of futures and building and reflecting final visions [45]. Initially, discussion rules were explicitly introduced. These are not very strict rules, but rather common-sense nudges regarding respectful communication. However, the facilitator asked everyone to agree, setting a baseline to which the group could return to in case of conflict. Organisational slots in the workshop design, such as breaks, introductions and ice breakers, are not further described in the following, rather focussing on content-related steps.

Sharing knowledge on the past At each table, a group of 6 to 8 participants shared knowledge on hopes, dreams and challenges they (or their parents/grandparents) have had in daily life 30-40 years ago. This step aimed at prompting a sense of opportunity for change over a longer period of time, whilst at the same time establishing group work and fosters group affiliation via communicating personal stories.

Visual inspiration and brainstorming Participants picked one or two images from a set of around 100 pictures displayed on each table, and discussed why they associate the image with hopes, dreams or fears in relation to the future. This step encouraged futures thinking and creativity, to facilitate individual inspiration and further foster group affiliation and team-work. CIMULACT used a standardised picture set, selected by an interdisciplinary group after all consortium members had the opportunity of submitting pictures. For the picture-set, selection criteria were established, e.g. displaying a broad spectrum of everyday content with relevance to societal challenges, no discriminating content, gender balance and no advertisement. Participants started very briefly writing down hopes, dreams and fears for a future in 3040 years. They were prompted to considering different perspectives, a self-centred, family and friend's point of view and a larger view concerning society (e.g. city, county and Europe).

Clustering of ideas, exhibition and presentation The facilitated generation of ideas on futures led to sharing and discussing ideas with the aim of clustering those. Participants started with identifying differences and commonalities in a bottom-up way, supported by a facilitator. Clustering results of all groups were exhibited besides each other and were presented to all other groups in plenum. This step served for providing an arena for sharing knowledge, cross-fertilisation of ideas, building common understanding and facilitating mutual learning. After presentations, participants were asked to pick one or two ideas that they would prefer to specify.

Imaginary time travel After an introduction to the concept of visions, a facilitator led participants through an imaginary journey into futures, which is based on principles of autogenic training. This provided a calm space for individual creativity and processing of the previously picked or other ideas. 
Individual futures Inspired by the time-travel or any other of the previous steps, participants created approximately one to two short narratives individually, based on a template. They were able to choose to develop whatever idea they preferred. The only restriction was a framing as desirable future within the timeframe of 2030-2040 and a description of why this future is important and to whom. Participants were allowed to use identified threats and fears as sources, however, were encouraged to briefly describe a future where these had been overcome or where measures had been taken for them not becoming real at all.

Shared futures After presenting the individual short narratives to each other, each group had the task to form two shared futures per table, so called 'raw-visions'. Via facilitated deliberation, participants built two narratives by merging, extending or simply selecting the individual futures.

Market of futures All shared futures were displayed in an exhibition easily accessible to all participants. A representative of each table presented the respective raw visions in plenum. This step aimed at fostering a shared understanding of desirable futures across the entire group. Afterwards, all participants silently voted (sticky dots) on which of the two futures of each table they prefer, being prompted to consider criteria such as clearness, uniqueness and creativity and importance. The voting outcome served as non-binding advice to each group, when picking one of the shared futures for further elaboration.

Building, reflecting and presenting visions Table groups deliberate of different parts of the selected future to elaborate it into a vision. This work is supported by the facilitator who repeatedly asks participants to specify their ideas and a template, which ensures relative comparability. Elaborated versions of the respective vision are then presented to other groups, gaining their feedback to then further elaborate and specify. This phase provides a space for mutual learning and reflexivity. Reflection on consequences and improvement of knowledge takes place in table groups, after final deliberation and wording visions are presented in plenum.

\section{Composition of participants and approach}

The guidelines for selecting the composition of participants invited to the visioning workshop were grounded on the basic assumption that building a sample of maximum heterogeneity leads to including a higher variety of different perspectives. Thus, each of the 30 national consultation invited 'around 36 participants, ensuring a high diversity within the following criteria: age, gender, education occupation and place of living. For example, six age groups were defined, ranging from 16 to 60 and older; to then have one member of each age group in all smaller working groups (table level). Four educational levels - pre-primary to higher education - and several occupation groups were defined to distribute participants at table level aiming at a high heterogeneity of backgrounds. The criterion of place of living ensured engaging city as well as country dwellers' [42]. These criteria were centrally developed and communicated along with training on recruitment strategies and guidelines to ensure that all national partners were able to recruit a composition with a high heterogeneity according to the discussed socio-demographics. Nevertheless, as each national partner acted within differing institutional settings and followed different strategies, e.g. some countries used professional recruiting agencies, whilst other selfrecruited. This resulted in an overall composition that diverged slightly from the aimed for with regard to an increased share of higher educated and older participants [46].

\section{Questionnaire design, assessment and limits}

The standardised questionnaire consisted of 19 multiple choice questions and an open commentary field. This relative briefness of the questionnaire, which overall took participants approximately 10-15 min to answer, limits the depth of analysis considerably. We deliberately chose this relative briefness for the following reasons: (a) collecting participants' impressions as they were undistorted and fresh; (b) achieving a high return rate and (c) not straining participants excessively at the end of an active 8-h workshop day. We considered a more elaborated ex-post evaluation survey, not conducted on site but mailed later, but expected considerably lower return rates, which we believe effects result strongly with bias towards answers of participants being well-disposed towards the project. Overall, we reached a return rate of 89 percent, but the questionnaire design is a compromise between possible depth of analysis and inclusivity. This brevity however limits the overall validity of the analysis.

Furthermore, the questionnaire was filled in anonymously, also without asking for basic socio-demographic data in the introductory section of the questionnaire. In our view, this approach provided less barriers for participants to answer genuinely. However, this also limits the depth of the results. Because we cannot provide a direct distribution in terms of socio-demographic data of the respondents, we are therefore unable to detect possible specific demographic shifts. For instance, if younger people answered differently than older participants, or female differently than males. Also, we are unable to compare the overall socio-demographics of all workshop 
participants with those taking part in the survey. The unaccounted for 11 percent of participants, could have belonged in majority to a specific group or two, which could have led to speculations about why they did not take part in the survey (e.g. because of dissatisfaction).

We analyse both, the affirmative and the sceptical reactions of participants regarding the visioning process and its results. Our analysis builds on an empirical basis of ex-post participant evaluation questionnaires $(n \approx$ 964), to deduce how the visioning process was assessed by the participants. Participants in all 30 countries received a standardised questionnaire at the end of the visioning workshop and anonymously filled it in on site. The questionnaire was developed in English and then translated into all national languages by the project team with support from the external evaluators. Each consortium partner conveyed their national data into a standardised analysis sheet, which was then aggregated as European sample by the project coordinator and transferred to work package leader (the authors). The standardised workshop setting, recruitment parameters and evaluation questionnaire provide high comparability and therefore allow us to deduce a trans-European assessment. We also refrain from assessing single countries' data to derive comparisons due to small sample size in the national settings.

\section{Results}

The return-rate of the evaluation questionnaire was approximately 89 percent-964 returned questionnaires in relation to 1088 overall participants of the citizen visioning workshop. The following sections describe four groups of questions regarding (a) participants' overall satisfaction with the event, (b) the climate of discussion during the workshop, (c) participants' evaluation of the quality of the final result (vision) they had worked on during the day, and (d) the purpose of the workshop (see all results in Table 1).

\section{Overall satisfaction}

About two-thirds of respondents' were very satisfied with the content of the workshop (64\%) and its practical organisation (73\%) and about one quarter was somewhat satisfied. Less than 5 percent of respondents' had a neutral position on these two questions and less than 1 percent respectively was somewhat or very dissatisfied with the event. On the question if respondents' initial expectations regarding the event had been met, approximately $45 \%$ were very satisfied and 47 percent somewhat satisfied, leaving $1.4 \%$ undecided and $5 \%$ somewhat dissatisfied.

\section{Discussion climate}

Respondents' evaluated the entire set of questions very positively, with between two-thirds and three quarters strongly agreeing and almost all remaining participants agreeing to statements such as 'I felt sufficiently comfortable and at ease to speak out and voice my opinions during the process' or 'I felt self-confident and able to formulate my views during the process at my table'. Comparable numbers can be observed with regard to if all participants were equally encouraged by facilitators to contribute, if the discussion climate was respectful and if facilitators ensured a fair and constructive process. For this entire set of questions, 'undecided' responses remained between 1.2 percent and 4.7 percent. Around 2 percent disagreed with the statement on equal encouragement and respectfulness. Less than 1 percent disagreed or strongly disagreed with the all other statements in this set.

\section{Quality of group vision}

A great majority of respondents' stated that the final product of the workshop-the vision they had worked on-expressed their personal views (40\% strongly agree, $49 \%$ agree), around 7 percent were undecided, 2 percent disagreed and 0.1 percent strongly disagreed. Satisfaction with the overall quality of the resulting vision shows almost the same results, as does the question if the influence of all participants on the final result was equal, with a slight deviation of 10 percent being undecided and $4.6 \%$ in disagreement. A great majority stated that the workshop setting encouraged their creativity (53.8\% strongly agree, $37.8 \%$ agree), $5.7 \%$ were undecided and $2.1 \%$ disagreed. Comparable results can be observed regarding if participants were able to reach consensus despite different opinions (51\% strongly agree, $44 \%$ agree, $3.1 \%$ undecided, with a combined $0.7 \%$ disagreeing or strongly disagreeing).

\section{Purpose of participation}

The first two statements show almost equal results, a combined $90 \%$ strongly agreeing and agreeing that the purpose of the workshop had been clearly communicated beforehand and that they clearly understood that purpose. Around 6\% were undecided whilst a combined 2-3\% disagreed and strongly disagreed. A combined $85 \%$ agreed or strongly agreed to that they know what will be done with the results after the workshop, $11.4 \%$ were undecided in this regard, a combined $3.8 \%$ disagreed or strongly disagreed. Around $80 \%$ were convinced that the created visions will 'inspire the future' (29.9\% strongly agree, $49.9 \%$ agree), $20 \%$ were undecided and a combined $5.7 \%$ disagree or strongly disagree. Ninety-three percent would again take part in a similar event and almost $99 \%$ stated that the EU should conduct more of such consultations in the future.

\section{Discussion-'inspiring the future'}

The overall results of the survey (return rate of $89 \%$ ) show that participants evaluated the visioning workshop 
Table 1 Overview of results from participants' evaluation of visioning workshop $(n \approx 964)$

\begin{tabular}{|c|c|c|c|c|c|c|}
\hline Overall satisfaction & $n^{3}$ & $\begin{array}{l}\text { Very } \\
\text { satisfied }\end{array}$ & $\begin{array}{l}\text { Somewhat } \\
\text { satisfied }\end{array}$ & Neutral & $\begin{array}{l}\text { Somewhat } \\
\text { dissatisfied }\end{array}$ & $\begin{array}{l}\text { Very } \\
\text { dissatisfied }\end{array}$ \\
\hline Overall, how satisfied have you been with the content of the event? & 959 & $64.3 \%$ & $29.2 \%$ & $4.8 \%$ & $0.5 \%$ & $0.4 \%$ \\
\hline $\begin{array}{l}\text { Overall, how satisfied have you been with the practical organisation } \\
\text { of the event? }\end{array}$ & 959 & $73.1 \%$ & $22.5 \%$ & $3.8 \%$ & $0.4 \%$ & $0.0 \%$ \\
\hline Did the event match with your initial expectations? & 949 & $45.3 \%$ & $47.5 \%$ & $1.4 \%$ & $5.2 \%$ & $0.6 \%$ \\
\hline Discussion climate & & $\begin{array}{l}\text { Strongly } \\
\text { agree }\end{array}$ & Agree & Undecided & Disagree & $\begin{array}{l}\text { Strongly } \\
\text { disagree }\end{array}$ \\
\hline $\begin{array}{l}\text { I felt sufficiently comfortable and at ease to speak out and voice } \\
\text { my opinions during the process. }\end{array}$ & 964 & $69.8 \%$ & $28.1 \%$ & $1.2 \%$ & $0.7 \%$ & $0.1 \%$ \\
\hline $\begin{array}{l}\text { I felt self-confident and able to formulate my views during the } \\
\text { process at my table. }\end{array}$ & 958 & $66.1 \%$ & $29.7 \%$ & $3.7 \%$ & $0.5 \%$ & $0.0 \%$ \\
\hline $\begin{array}{l}\text { My impression is that all participants to the discussion at my table } \\
\text { were equally encouraged to participate. }\end{array}$ & 963 & $65.3 \%$ & $28.5 \%$ & $3.9 \%$ & $2.1 \%$ & $0.2 \%$ \\
\hline The participants all were respectful towards one another. & 959 & $75.0 \%$ & $21.6 \%$ & $1.9 \%$ & $1.6 \%$ & $0.0 \%$ \\
\hline $\begin{array}{l}\text { The moderators did a good job in ensuring a constructive and fair } \\
\text { process during the discussions. }\end{array}$ & 960 & $71.7 \%$ & $22.9 \%$ & $4.7 \%$ & $0.6 \%$ & $0.1 \%$ \\
\hline \multicolumn{7}{|l|}{ Quality of group vision } \\
\hline The elaborated vision from my group expressed my personal views. & 959 & $40.9 \%$ & $49.8 \%$ & $6.7 \%$ & $2.5 \%$ & $0.1 \%$ \\
\hline $\begin{array}{l}\text { The influence of the participants at my table on the final } \\
\text { formulation of the vision was balanced. }\end{array}$ & 959 & $40.5 \%$ & $43.9 \%$ & $10.6 \%$ & $4.6 \%$ & $0.4 \%$ \\
\hline I'm satisfied with the overall quality of the elaborated visions. & 954 & $40.4 \%$ & $49.0 \%$ & $8.3 \%$ & $2.1 \%$ & $0.3 \%$ \\
\hline $\begin{array}{l}\text { The working atmosphere at the citizen panel encouraged my } \\
\text { creativity. }\end{array}$ & 957 & $53.8 \%$ & $37.8 \%$ & $5.7 \%$ & $2.5 \%$ & $0.1 \%$ \\
\hline Despite different opinions we were able to reach consensus. & 956 & $51.6 \%$ & $44.6 \%$ & $3.1 \%$ & $0.6 \%$ & $0.1 \%$ \\
\hline \multicolumn{7}{|l|}{ Purpose of participation } \\
\hline The purpose of the day was well communicated beforehand. & 949 & $52.3 \%$ & $40.5 \%$ & $5.8 \%$ & $1.3 \%$ & $0.2 \%$ \\
\hline I had a clear understanding of the purpose of this day. & 942 & $53.0 \%$ & $38.7 \%$ & $5.5 \%$ & $2.3 \%$ & $0.4 \%$ \\
\hline $\begin{array}{l}\text { It is clear to me what will be done with the results of the } \\
\text { discussions today. }\end{array}$ & 827 & $45.2 \%$ & $39.5 \%$ & $11.4 \%$ & $3.0 \%$ & $0.8 \%$ \\
\hline \multirow{2}{*}{$\begin{array}{l}\text { I am convinced that the visions created today will serve to inspire } \\
\text { the future. }\end{array}$} & 877 & $29.9 \%$ & $49.6 \%$ & $20.1 \%$ & $5.1 \%$ & $0.6 \%$ \\
\hline & & Yes & No & & & \\
\hline Would you take part in such an event again? & 958 & $93.0 \%$ & $7.0 \%$ & & & \\
\hline $\begin{array}{l}\text { Do you think that the EU should engage citizens in the future in } \\
\text { this kind of activities? }\end{array}$ & 957 & $98.7 \%$ & $1.3 \%$ & & & \\
\hline
\end{tabular}

${ }^{3} 1088$ participants received the questionnaire, 964 returned it. Differing $\mathrm{n}$ resulted from some participants omitting some questions

very positively. When combining the results of the two affirmative answer categories (very satisfied, somewhat satisfied and strongly agree, agree), most statements in the questionnaire show affirmative results of around or more than $90 \%$. The combined negative answer categories range between less than 1 and $5 \%$. This clearly indicates that a great majority was overall satisfied with the content, results, organisation and facilitation of the visioning workshops in all 30 European countries. This European scale supports the conclusion that participants valued the visioning process during the workshops.

Letting participants fill in the evaluation questionnaire on site led to the very high return rate of approximately $89 \%$, and collects impressions that are still very fresh. On the one hand, this is a favourable result for any questionnaire-based survey; however, proceeding this way may have the disadvantage of not leaving the participants enough time to reflect their experience, thus rushing them into judgement after a long and exhaustive working day. Even though they returned the questionnaire anonymously, filling it in at the workshop site may bias them towards answering more positively than they would alone, at home and after a couple of days. However, sending the questionnaire later from home may also provoke a bias towards receiving more answers from participants that prefer to further collaborate with the researchers and thus, e.g. more positive answers. Nevertheless, the brevity limits the overall validity of the analysis. We cannot conclusively exclude the possibility that, for instance, other factors than the process of engagement contributed to the high overall satisfaction of the respondents, e.g. atmosphere, incentives or catering. 
Interestingly, one question shows less affirmative support from participants. Overall 80\% (combined affirmative categories) believed that the created visions would 'inspire the future', nevertheless of these $80 \%$ only around 30\% strongly agree, by far the lowest score in this most affirmative answer category. All other questions resulted in between 40 and $75 \%$ of strong agreement. Also, regarding 'inspiring the future', $20 \%$ were undecided; in comparison to all other questions, this is also by far the highest number in this answer category. Notably both negative answer categories show similar low results as those for the other statements. This result testifies to an insecurity of respondents' about the impact of this public engagement and should be studied in future according to different assumptions: (1) Respondents' did like the workshop and their vision; however, they do not trust in the impact of consultations to inflict change on political and economic agendas. This could be driven by recurring fluctuations of trust in and critical attitude towards (political) institutions, such as the EU $[47-49]^{3}$, and/or the low political-hierarchical status of consultations, i.e. non-binding inquiries [52, 53]. (2) Respondents' did like the workshop and their visions; however, they did not trust the impact of narratives on desirable futures (visions) to inflict change on political and economic agendas. (3) Respondents' are possibly well aware of the dominant rationalities in European Union agenda setting, i.e. competitiveness and economic development [32], which are to some degree antagonistic to the citizens' priorities. Hence, the respondents' distrust visions that follow alternative rationalities or priorities. (4) Also a limited trust in not only the management of the interface between knowledge production (visions) and policy makers but also insufficient understanding that knowledge itself (and hence visions and what can be deduced thereof) may be conceived an intrinsic part of governance [54].

The statement regarding 'inspiring the future' does neither specify the kind of change nor at what level. Within the context of the consultation, many respondents' may have answered the question with an understanding of the communicated main aim of the project: influencing European Union and national R\&D policy. However, anecdotal evidence ${ }^{4}$ from discussions with participants and the open ended commentary field in the questionnaire in this

\footnotetext{
${ }^{3}$ Trust in government is a multifaceted and complex concept and its relation to democracy is somewhat paradoxical as in a representative democracy citizens 'trust' the elected with their vote, whilst at the same time healthy scepticism towards the government leading to a monitoring of its actions is a main democratic principle [50, 51]. ${ }^{4}$ Since the open commentary field provided very few answers other than very generalised feedback to the workshop, content cannot be analysed in a structured way, and is thus only referred to as 'anecdotal' evidence.
}

project as well as other similar projects [35] suggests that 'inspiring the future' can also be understood at a personal level. As all participants formulate their personal visions in the beginning of the workshop and a great majority is convinced that the final vision at their table reflects their personal views, change may also have been understood in terms of personal or peer futures. If this was the case, power of implementation lays in part in the hands of the visionaries.

\section{Methodological considerations}

As shown above, the visioning process leads to group products, a fact that in itself has several implications. Even if the majority of participants were content with their group's final vision, the group process is designed as to achieve consent, which may lead to mainstreaming of initial ideas, but as argued earlier and elsewhere adds social robustness to the visions [35]. Independent visioning of individuals is not the aim of this deliberative process. This however opens up questions such as what is lost in the recurring cycles of feedback and deliberation in terms of creativity and opinion outliers (as opposed to what is gained). Would independent visioning of individuals lead to a higher diversity in the resulting portfolio of visions and thus produce more creative output in order to 'inspire and open up new paths into the future which hitherto were considered impossible' [8]? Whilst this may be possible, we cannot answer these questions is the scope of this article, but they need to be considered in future practices. Here, there is a need to specifically examine a key point in the visioning process: the transition from the very short individual narratives (individual futures) to collective products (shared futures). If there is a loss of creativity, this transition could possibly be improved.

Another crucial point for potential loss of diversity of opinions is the market of visions, where individual voting on the shared futures takes place and thus opinion outliers may be excluded from further processing. Nevertheless, the collective visioning process may overall benefit from the collective creativity as the co-creation of knowledge harnesses the diversity of perspectives of participants and allows for mutual learning and inspiration. Collective creativity outperforming individual creativity has for instance been shown for brainstorming exercises and organisational innovation $[55,56]$.

Participatory visioning activities may also exhibit the 'veil of ignorance' effect that was described for participatory scenario building. Whilst discussing an uncertain future, participants may intuitively 'smooth out tensions that are inevitably embedded in scenarios' which 'reflect participant concern for fair future interaction' between all groups in society [57]. Such an effect is supported by a timeframe that is sufficiently far away to minimise 
threats to participants resulting from unresolved tensions [58]. These tensions, however, would again present an aimed for learning opportunity for informing todays decisions, which are obscured under the described effect.

Another crucial point in the overall agenda setting methodology (see Fig. 1) that may need in depth review in future exercises: the shift from national or even regional participatory activities to a trans-European level. This transition may put previously co-created knowledge under pressure, because very specific regional/national issues (or nuances of issues) may possibly be lost due to mainstreaming effects, which may not be detected in the second national consultation phases. This could have a profound effect on the aimed for regional/national impacts of the agenda setting activity.

\section{Conclusions}

In this article, we have investigated a standardised transEuropean visioning process that engaged more than 1000 laypeople in 30 European countries for research and innovation agenda setting. We provided insights into the method of this visioning process itself and presented data from an ex-post participant evaluation survey. The discussed data showed that a very large majority of the participants were content with the visioning process and its products. The data furthermore showed that the applied workshop method and facilitation lead to a very high approval with regard to ensuring a fair and balanced environment for creative visioning and deliberation. Nevertheless, participants were sceptical about the impact of results. Overall, the visioning process posed the simple, yet fundamentally important question of 'How do we want to live in the future?' The process itself was not conceptualised to deal with this scepticism. Participants were invited as co-creators, throughout major parts of the CIMULACT project. The positioning and rationality of this citizen-based participatory agenda setting activity within the greater ecosystem of EU research and innovation governance however only allowed a limited influence on the policy making, which was also communicated beforehand.

In future, it should be considered that the visions created by citizens seldom provide quantifiable targets or goals that would be simple and directly easy to incorporate into research and innovation agenda setting. Their benefit lays elsewhere: the visions uncover and provide alternative rationalities, values and realities that may serve as important counter-weights to state-of-the-art policy and its priorities and hence the business as usual. Within the described larger framework of the participatory agenda setting activity, they built a stepping stone for engaging other relevant groups such as stakeholders and policymakers. The visions primed the entire agenda setting process with the citizens' ideas of how the future should be like-thus democratising utopian thought and shaping futures. However, to do so, such a democratisation process should include more direct interaction of local and national and EU policy makers with citizens. A recent analysis showed that citizen-based foresight activities provide distinctly different results than expert-based activities [37]. Yet, in classical multi-actor settings, there is a distinct risk of misrepresenting citizens' original ideas when experts and policy specialists transform the initial visions into research topics or policy recommendations. A clear reason to stick with feedback-loops for the citizens to monitor how their ideas are further processed. Repo and Matschoss [41] examined a process somewhat similar to CIMULACT, and conclude that experts had specifically favoured 'technically oriented, systemic citizen visions over societal and personal ones', when prioritising and drafting recommendation based on the visions. In a multistep agenda setting process, several provisions need to be taken to ensure authenticity of the citizens' input throughout the activity. Provisions such as inviting citizens as representants of the visions to a co-creation event that engaged experts and stakeholders to draft research topics and recommendations from the visions content, putting the visions on visual display throughout those activities, or prompting facilitators beforehand to ask participants at strategic points of the event to check if the developed content was still representing the initial ideas as expressed in the visions. In CIMULACT, a second citizen consultation phase, where participants assessed and further elaborated the draft research topics, provided another checking point.

Considering the numerous caveats for decreasing authenticity necessarily attached to complex multi-step processes calls for communicating citizen-originated content of participatory activities in its original form; however, a transformation process was necessary in order to reach the goal of producing tangible research topics, compatible to the political and expert-driven rationalities of transnational research and innovation agenda setting in the EU. On the one hand, such a largescale consultation processes may provide a strong basis for its participants to trust in its significance; on the other, this may contribute to the contrary: foster distrust in its impact as the individual voice and the citizens' power may drown in the interplay of forces of the whole process. Within CIMULACT, researchers and practitioners reacted to this possibility by publishing and communicating the citizens' visions as a stand-alone result.

Overall, harnessing citizens' creativity by collective visioning activities is a path worth following if the aim is to include societal needs and values into research and innovation from early on in the agenda setting phase. This process allows for uncovering an undistracted 
collective view of laypeople on desirable futures, which could even be tailored methodologically to fit particular needs when setting agendas for more specific research areas than an entire EU research programme. This could in fact be a very promising endeavour, since more specific boundaries of such a process may allow for more specific visions. These may then be harder to be weakened, watered down or disregarded by experts in later participatory agenda setting steps, thus improving authenticity of final outputs of exercises.

The fact that such a large-scale process based on citizens' visions was commissioned and conducted within the time-, content- and stake-sensible bargaining arena of framing a pan-European research and innovation agenda may be rated as a success in designing more responsive research and innovation. Nevertheless, as critical outlook, we ask how do the following facts render a large-scale participatory process: (a) citizens are in retrospective content with their participation, (b) they would participate again in a similar event, (c) they prefer that the EU hosts such events in the future, but (d) they are somewhat unsure if the results actually have an impact on the stated aim of research and innovation agenda setting. This shows that the impact of a participatory agenda setting activity on research and innovation governance needs to become transparently traceable. Otherwise, without such a plausible link between knowledge co-creation and governance, the commissioning institutions' trustworthiness may suffer.

\section{Abbreviations}

CIMULACT: Citizen and Multi-Actor Consultation on Horizon 2020; CSA: Coordination and support action; EU: European Union; EC: European Commission; STI: Science, technology and innovation; SWAFS: Science with and for society

\section{Acknowledgements}

We thank the entire CIMULACT consortium (3029 partner institutions) for their collaboration in distributing and collecting the questionnaire, Sune Schøning (Danish Board of Technology) for support in aggregating data and Sylvia Breukers (DuneWorks) for her valuable feedback as external evaluator on the questionnaire.

\section{Authors' contributions}

N.G. shaped the presented research and took the lead in writing the manuscript. All authors provided critical feedback and analysis and added to the manuscript. The authors read and approved the final manuscript.

\section{Funding}

The data was produced and part of the analysis was conducted within the EU project CIMULACT, funded under the call H2020-ISSI-2014-2015: Call for integrating Society in Science and Innovation, Topic ISSI-2-2014: Citizens and multi-actor engagement for scenario building. Another part of the analysis was internally funded by the Institute of Technology Assessment (ITA) of the Austrian Academy of Sciences.

Availability of data and materials Not applicable

\section{Declarations}

Ethics approval and consent to participate

Not applicable

\section{Consent for publication}

Not applicable

\section{Competing interests}

The authors declare that they have no competing interests.

Received: 29 July 2019 Accepted: 10 May 2021

Published online: 31 May 2021

\section{References}

1. Kabadayi C, Osvath M (2017) Ravens parallel great apes in flexible planning for tool-use and bartering. Science 357(6347):202-204. https://doi.org/10.112 6/science.aam8138

2. Perry CJ, Chittka L (2019) How foresight might support the behavioral flexibility of arthropods. Curr Opin Neurobiol 54:171-177. https://doi.org/1 0.1016/j.conb.2018.10.014

3. Konrad K, Böhle K (2019) Socio-technical futures and the governance of innovation processes - an introduction to the special issue. Futures 109: 101-107. https://doi.org/10.1016/j.futures.2019.03.003

4. van der Helm R (2007) Ten insolvable dilemmas of participation and why foresight has to deal with them. Foresight 9(3):3-17. https://doi.org/10.11 08/14636680710754138

5. Fernando JW, Burden N, Ferguson A, O'Brien LV, Judge M, Kashima Y (2018) Functions of utopia: how utopian thinking motivates societal engagement. Personal Soc Psychol Bull 44(5):779-792. https://doi.org/10.1177/014616721 7748604

6. Harlow J, Golub A, Allenby B (2013) A review of utopian themes in sustainable development discourse. Sustain Dev 21(4):270-280. https://doi. org/10.1002/sd.522

7. Miller J (1998) Post-apocalyptic hoping: Octavia Butler's dystopian/utopian vision. Sci Fict Stud 25(2):336-360

8. Berenskoetter $F(2011)$ Reclaiming the vision thing: constructivists as students of the future1. Int Stud Q 55(3):647-668. https://doi.org/10.1111/ j.1468-2478.2011.00669.x

9. Hedrén J, Linnér B-O (2009) Utopian thought and sustainable development. Futures 41(4):197-200. https://doi.org/10.1016/j.futures.2008.09.002

10. Goodwin B, Taylor K (1982) The politics of utopia: a study in theory and practice. Hutchinson

11. Levitas R (2013) Utopia as method: the imaginary reconstitution of society. Palgrave Macmillan, Basingstoke. https://doi.org/10.1057/9781137314253

12. Tepper A (1996) Controlling technology by shaping visions. Policy Sci 29(1): 29-44. https://doi.org/10.1007/BF00141478

13. Wiek A, Iwaniec D (2014) Quality criteria for visions and visioning in sustainability science. Sustain Sci 9(4):497-512. https://doi.org/10.1007/s1162 5-013-0208-6

14. Wiek A, Farioli F, Fukushi K, Yarime M (2012) Sustainability science: bridging the gap between science and society. Sustain Sci 7(S1):1-4. https://doi.org/1 0.1007/s11625-011-0154-0

15. Sand M, Schneider C (2017) Visioneering socio-technical innovations - a missing piece of the puzzle. NanoEthics 11(1):19-29. https://doi.org/10.1007/ s11569-017-0293-6

16. Dierkes M, Hoffmann U, Marz L (1996) Visions of technology, social and institutional factors shaping the development of new technologies. CampusVerlag, Frankfurt/Main, NewYork

17. McCray P (2012) California dreaming: visioneering the technological future, in the visioneers how a group of elite scientists pursued space colonies, nanotechnologies, and a limitless future. Princeton University Press, pp 183-221

18. Dignum M, Correljé A, Groenleer M, Scholten D (2018) Governing through visions: evaluating the performativity of the European gas target models. Energy Res Soc Sci 35:193-204. https://doi.org/10.1016/j.erss.2017.10.016

19. Jasanoff $S$ (2016) The ethics of invention: technology and the human future The Norton Global Ethics Series (1st ed.). W.W. Norton \& Company, New York, London

20. Sand M (2019) On "not having a future". Futures 107:98-106. https://doi. org/10.1016/j.futures.2019.01.002 
21. Schneider C, Lösch A (2019) Visions in assemblages: future-making and governance in FabLabs. Futures 109:203-212. https://doi.org/10.1016/j. futures.2018.08.003

22. Callaghan CW (2018) Surviving a technological future: technological proliferation and modes of discovery. Futures 104:100-116. https://doi.org/1 0.1016/j.futures.2018.08.001

23. Nikolova B (2013) The rise and promise of participatory foresight. Eur J Fut Res 2(1)

24. Joss S, Bellucci S (2002) Participatory technology assessment - European perspectives. University of Westminster, London

25. Popp R (2013) Participatory futures research. Research or practice consulting? Eur J Fut Res 1(1)

26. Stirling A (2007) "Opening Up" and "Closing Down": power, participation, and pluralism in the social appraisal of technology. Sci Technol Hum Values 33(2):262-294

27. Grunwald A (2019) The inherently democratic nature of technology assessment. Sci Public Policy 46(5):702-709. https://doi.org/10.1093/ scipol/sczO23

28. Pinto Jean P, Medina J (2020) Hybrid processes for a new era of strategic foresight. Foresight 22(3):287-307

29. Voss JP, Amelung N (2016) Innovating public participation methods: technoscientization and reflexive engagement. Soc Stud Sci 46(5):749-772. https://doi.org/10.1177/0306312716641350

30. Burget M, Bardone E, Pedaste M (2017) Definitions and conceptual dimensions of responsible research and innovation: a literature review. Sci Eng Ethics 23(1):1-19. https://doi.org/10.1007/s11948-016-9782-1

31. Conceição CP et al (2019) European action plans for science-society relations: changing buzzwords, changing the agenda. Minerva

32. Eizagirre A, Rodríguez H, Ibarra A (2017) Politicizing responsible innovation: responsibility as inclusive governance. Int J Innov Stud 1(1):20-36. https:// doi.org/10.3724/SP.J.1440.101003

33. Stirling A (2007) Deliberate futures: precaution and progress in social choice of sustainable technology. Sustain Dev 15(5):286-295. https://doi.org/10.1 002/sd.347

34. Braun K, Könninger S (2017) From experiments to ecosystems? Reviewing public participation, scientific governance and the systemic turn. Public Underst Sci 27(6):674-689. https://doi.org/10.1177/0963662517717375

35. Gudowsky N, Sotoudeh M (2017) Into blue skies-a transdisciplinary foresight and co-creation method for adding robustness to visioneering. NanoEthics 11(1):93-106. https://doi.org/10.1007/s11569-017-0284-7

36. Repo P, Matschoss K, Timonen P (2017) Sustainable futures: comparing methodologies for analyzing citizen visions in Europe. Soc Stud 7(5):246-262

37. Gudowsky N, Rosa A (2019) Bridging epistemologies - identifying uniqueness of lay and expert knowledge for agenda setting. Futures 109: 24-38. https://doi.org/10.1016/j.futures.2019.04.003

38. Rosa A, Gudowsky N, Warnke P (2018) But do they deliver? Participatory agenda setting on the test bed. Eur J Fut Res 6(1)

39. Sotoudeh M, Gudowsky N (2018) Participatory foresight for technology assessment - towards an evaluation approach for knowledge co-creation. TATuP - Zeitschrift für Technikfolgenabschätzung in Theorie und Praxis 27(2):53-59

40. Jørgensen M-L, Schøning S (2016) CIMULACT Deliverable 1.3: vision catalogue - encompassing the visions from all 30 countries

41. Repo P, Matschoss K (2019) Considering expert takeovers in citizen involvement processes. J Resp Innov 6(2):119-142. https://doi.org/10.1 080/23299460.2019.1568145

42. Gudowsky N, Peissl W (2016) Human centred science and technology - transdisciplinary foresight and co-creation as tools for active needs-based innovation governance. Eur J Fut Res 4(1)

43. Gudowsky $N$ et al (2017) Contributing to an European imaginary of democratic education by engaging multiple actors in shaping responsible research agendas. Special issue 'Participatory Methods for Information Society'. Public Phil Democratic Edu 5(2):29-50

44. Hebáková L et al (2018) CIMULACT Deliverable 5.3-report on the impact of the project. Technology Centre of the Czech Academy of Sciences (TC CAS)

45. Dagorne E, Gudowsky N (2018) CIMULACT Deliverable 5.1 - inspiration catalogue for consulting different groups. Missions Publiques, France

46. Breukers, S., et al., CIMULACT Deliverable 7.1 - external evaluation Report 1. 2016.

47. Foster C, Frieden J (2017) Crisis of trust: socio-economic determinants of Europeans' confidence in government. Eur Union Pol 18(4):511-535. https:// doi.org/10.1177/1465116517723499
48. EC, Special Eurobarometer 461 - "Designing Europe's future": trust in institutions globalisation support for the Euro, opinions about free trade and solidarity, D.-G.f.C. European Commission, Editor. 2017.

49. OECD (2017) Trust and public policy: how better governance can help rebuild public trust. In: OECD Public Governance reviews. OECDpublishing, Paris

50. Christensen T, Lægreid $P$ (2005) Trust in government: the relative importance of service satisfaction, political factors, and demography. Public Perform Manag Rev 28(4):487-511

51. Tom, W.G.v.d.M (2017) Political trust and the "Crisis of Democracy". Oxford University Press

52. Arnstein SR (1969) A ladder of citizen participation. J Am Plan Assoc 35(4): 216-224

53. Rowe G, Frewer LJ (2005) A typology of public engagement mechanisms. Sci Technol Hum Values 30(2):251-290. https://doi.org/1 $0.1177 / 0162243904271724$

54. van der Molen F (2018) How knowledge enables governance: the coproduction of environmental governance capacity. Environ Sci Pol 87:1825. https://doi.org/10.1016/j.envsci.2018.05.016

55. Parjanen S (2012) Experiencing creativity in the organization: from individual creativity to collective creativity. Interdiscip J Inf Knowl Manag:7

56. Tadmor CT, Satterstrom P, Jang S, Polzer JT (2012) Beyond individual creativity: the superadditive benefits of multicultural experience for collective creativity in culturally diverse teams. J Cross-Cult Psychol 43(3): 384-392. https://doi.org/10.1177/0022022111435259

57. Andreescu L, Gheorghiu R, Zulean M, Curaj A (2013) Understanding normative foresight outcomes: scenario development and the 'veil of ignorance' effect. Technol Forecast Soc Chang 80(4):711-722. https://doi. org/10.1016/j.techfore.2012.09.013

58. Bonaccorsi A, Apreda R, Fantoni G (2020) Expert biases in technology foresight. Why they are a problem and how to mitigate them. Technol Forecast Soc Chang 151:119855

\section{Publisher's Note}

Springer Nature remains neutral with regard to jurisdictional claims in published maps and institutional affiliations.

\section{Submit your manuscript to a SpringerOpen ${ }^{\circ}$ journal and benefit from:}

- Convenient online submission

- Rigorous peer review

- Open access: articles freely available online

High visibility within the field

- Retaining the copyright to your article

Submit your next manuscript at $\boldsymbol{\nabla}$ springeropen.com 